\title{
TRENDOVI E-POSLOVANJA U USLUŽNOJ DELATNOSTI
}

\author{
Dr Ana Skorup \\ Visoka škola za poslovnu ekonomiju i preduzetništvo Beograd, Visoka poslovna škola \\ strukovnih studija „Prof. dr Radomir Bojković“ Kruševac \\ e-mail: anaskorup@gmail.com
}

\section{Dr Milan Krstić}

Visoka škola za poslovnu ekonomiju i preduzetništvo Beograd e-mail: mykrstic@gmail.com

\section{Mr Maja Cogoljević}

Visoka škola za poslovnu ekonomiju i preduzetništvo Beograd

\section{Sažetak}

Aktuelne trendove poslovanja na globalnom planu karakteriše razvoj ekonomije bazirane na znanju čije su glavne odrednice: razvoj interneta i e - poslovanja, nastavak procesa globalizacije, specijalizacija $i$ svetska podela rada, sve kraći životni vek proizvoda, razvoj globalnih lanaca snabdevanja od strane multinacionalanih kompanija, glokalizacija, razvoj preduzetništva i sektora malih i srednjih preduzeća (MSP). Ovaj rad se fokusira na jednu od navedenih karakteristika digitalne ekonomije, odnosno e-poslovanje, budući da je ono već danas preovladavajući metod rada (a u budućnosti će biti $i$ predominantan), sa posebnim naglaskom na njegovoj primeni u uslužnim delatnostima. Uslužna delatnost je područje ljudske delatnosti $u$ kome se sve više zapošljava radno aktivno stanovništvo, odnosno oblast rada u kojoj postoji latentan potencijal za zapošljavanjem radne snage. Stoga se u radu najpre razmatra e-poslovanje sa sledećih stanovišta: definicije, razvoja, prednosti $i$ nedostataka, karakteristika informatičkog društva. Potom se detaljnije razmatra uslužna delatnost, a stanovišta sa kojih se to čini su: privredni sektor, uslužni sektor, usluge, uslužni proizvod, usluge i nove tehnologije. Zatim se daje osvrt na budući trend kroz razmatranje relevantnih dimenzija i osobenosti uslužnih inovacija. Na kraju se daje zaključak u kome se izvode konstatacije vezano za aktuelni $i$ budući trend $e$ poslovanja i uslužnih delatnosti.

\section{Abstract}

Current business trends at the global level are characterized by the development of knowledge-based economy, whose main characteristics are: the development of the Internet and e-business, continual process of globalization; specialization and the global division of labor, progressively shorter product expectancy, the development of global supply chains by multinational companies, glocalization, entrepreneurship and the Small and Medium Enterprises (SMEs). This paper focuses on one of the mentioned characteristics of digital economy - e-business, as it is today the prevalent method of work (and in the future will be the predominant), with special emphasis put on its application in the service industry. Service industry is an area of human activity which increasingly employs working population in a working area of latent 
potential for labor employment. Therefore, this paper discusses the e-business from the next aspects: the definition, development, advantages and disadvantages and characteristics of the information society. Afterwards, service industry is discussed from the next points: economic sector, service sector, service, service product, service and new technologies. The paper then looks at the future trends through consideration of the relevant dimensions and characteristics of service innovation. The paper ends with a conclusion drawn in relation to the current and future trend of ebusiness and service industries.

Ključne reči: privreda, uslužni sektor, usluga, uslužni proizvod, e-poslovanje, inovacije

Key words: economy, the service sector, service, product service, e-business, innovation

\section{Uvod}

Aktuelni trendovi poslovanja na globalnom planu, a koji vladaju u okruženju savremenih poslovnih subjekata, imaju sledeće karakteristike, i to: razvoj ekonomije bazirane na znanju; razvoj interneta i e poslovanja; nastavak procesa globalizacije; specijalizacija i svetska podela rada; sve kraći životni vek proizvoda; razvoj globalnih lanaca snabdevanja od strane multinacionalanih kompanija; glokalizacija „razmišljaj globalno radi lokalno”, razvoj preduzetništva i MSP sektora [1].

Razvoj ekonomije bazirane na znanju je pored tradicionalnih proizvodnih faktora (rad i kapital), inaugurisao intelektualni kapital za dominantni faktor aktuelne ekonomske paradigme, što je za posledicu proizvelo potrebu izdvajanja značajnih sredstava za istraživanje i razvoj, kao i infrastrukturnu podršku inovativnoj delatnosti, prevashodno $\mathrm{u}$ oblasti novih tehnologija.

Razvoj interneta i elektronskog poslovanja omogućili su individualnim i korporativnim korisnicima ne samo da dođu do relevantnih informacija u različitoj formi (fajl, video zapis, muzički zapis i sl.), već i da te informacije stave u aktivnu funkciju svog poslovanja. Razvoj interneta i pratećih poslovnih servisa, kao što su e-trgovina, emarketing, e-bankarstvo, e-vlada i dr, podstiče dalji razvoj i ekspanziju procesa globalizacije.

Nastavak procesa globalizacije, pri čemu se globalizacija može posmatrati sa različitih aspekata, kao globalna ekonomska, finansijska i trgovinska razmena, kao kulturološki fenomen, kao politički i vojni aspekat i sl. Razvoj IKT podstiče dalji razvoj globalizacije, ona podstiče dalji razvoj IKT koje su stvorile nove mogućnosti i načine rada koji pre nisu postojali.

Specijalizacija $i$ svetska podela rada su jedna od posledica procesa globalizacije. $\mathrm{Na}$ osnovu analiza svojih komparativnih prednosti, zemlje se opredeljuju za dugoročni razvoj onih delatnosti, za koje ocenjuju da postoje najpovoljniji uslovi, čime se ostvaruje optimalan odnos upotrebe nacionalnih resursa i ostvarenih efekata. $\mathrm{Na}$ taj način pojedine zemlje postaju lideri poslovanja u određenim oblastima.

Sve kraći životni vek proizvoda je rezultat delovanja dva ključna faktora: razvoja novih tehnologija, posebno informaciono komunikacionih tehnologija (IKT), i globalne konkurencije.

Multinacionalni globalni lanci snabdevanja su poslovni lanci koje formiraju transnacionalne kompanije u cilju zadržavanja svoje konkurentske pozicije kroz dislokaciju svoje proizvodnje u one delove sveta gde za to postoje najpovoljniji ekonomski uslovi, a što za posledicu ima stvaranje dugačkih lanaca snabdevanja sa složenom logistikom.

Glokalizacija je nova jezička kovanica (engl. glocalisation) nastala od marketinške sintagme „razmišljaj globalno radi lokalno“, i predstavlja neku vrstu saveta preduzetnicima da tragaju za načinima da se globalni trendovi implementiraju na lokalnom nivou.

Razvoj preduzetništva $i$ MSP sektora je specifičan razvoj kojim se sugeriše 
stvaranje novih kreativnih ideja za proizvode i usluge, kao i njihova primena (odnosno komercijalizacija) u cilju daljeg preduzetničkog delovanja kroz sektor MSP.

Sve navedene karakteristike se manifestuju u obliku globalnih ekonomskih kretanja i determinišu digitalnu ekonomiju današnjice. Nesumnjivo je da one imaju značajnog odraza na način poslovanja privrednih subjekata, nasuprot e-poslovanju, tradicionalno.

Tradicionalno poslovanje zasnovano je na korišćenju strukturiranih papirnih dokumenata $u$ prethodno definisanoj i opšteprihvaćenoj komunikaciji između učesnika u procesu poslovanja.

E-poslovanje predstavlja razmenu standardizovanih elektronskih poruka $\mathrm{u}$ obavljanju raznih poslova u kompanijama, bankama, upravi, aktivnostima građana i u svim drugim poslovnim transakcijama.

Ovaj rad se fokusira na jednu od navedenih karakteristika digitalne ekonomije, odnosno e-poslovanje, budući da je ono već danas preovladavajući metod rada (a u budućnosti će biti i predominantan), sa posebnim naglaskom na njegovu primenu u uslužnim delatnostima.

Uslužna delatnost je područje ljudske delatnosti u kome se sve više zapošljava radno aktivno stanovništvo, odnosno oblast rada u kojoj postoji latentan potencijal za zapošljavanje radne snage.

Stoga se u radu najpre razmatra e-poslovanje sa sledećih stanovišta: definicije, razvoja, prednosti i nedostataka, karakteristika informatičkog društva.

Potom se detaljnije razmatra uslužna delatnost, a stanovišta sa kojih se to čini su: privredni sektor, uslužni sektor, usluge, uslužni proizvod, usluge i nove tehnologije.

Zatim se daje osvrt na budući trend kroz razmatranje relevantnih dimenzija i osobenosti uslužnih inovacija.

$\mathrm{Na}$ kraju se daje zaključak u kome se izvode konstatacije vezano za aktuelni i budući trend e-poslovanja i uslužnih delatnosti.

\section{E - poslovanje}

Termin e-poslovanje (engl. "e-business") koristi se prvi put u IBM-u 1997. godine, da bi se istakla konceptualna distinkcija sa do tada upotrebljavanim terminom "ecommerce" (elektronska trgovina), koji je izjednačavao elektronsko poslovanje sa elektronskom trgovinom.

Još uvek ne postoji jedinstvena i opšteprihvaćena definicija elektronskog poslovanja, s obzirom na veliki varijetet njegovih pojavnih oblika [2].

\subsection{Definisanje e-poslovanja}

E - poslovanje predstavlja način organizacije poslovanja u mrežnom okruženju koje je zasnovano na primeni IKT, a posebno interneta.

E-poslovanje je opšti koncept poslovanja koji obuhvata sve oblike poslovnih transakcija na relaciji kompanija- kompanija, kompanijakorisnik, kompanija- javna administracija, a koje se sprovode primenom IKT.

E-poslovanje je poslovna transformacija zasnovana na:

- udruživanju kompanija (integracija),

- procesu saradnje (kolaboracija),

- globalnom mrežnom povezivanju koriš-ćenjem interneta kao medija (umreža-vanje).

Najvažnije aktivnosti e-poslovanja su:

- prikupljanje podataka i informacija;

- marketing (4P - marketing miks promocija, podrška kupcima, uvođenje novog proizvoda);

- onlajn prodaja (proizvoda i usluga);

- komunikacija [3].

E-poslovanje je integracija poslovnih procesa, preduzetničkih operacija i organizacione strukture, neophodnih za stvaranje visokoefikasnog modela poslovanja.

E - poslovanje je skup poslovnih aktivnosti koje se odvijaju posredstvom IKT, a posebno interneta, i koje podrazumevaju unapređenje:

- lanca glavnih poslovnih aktivnosti (proiz-vodnja, marketing, veleprodaja, 
distribu-cija, prodaja, naplata, isporuka, dopuna zaliha)

- odnosa sa stejkholderima (korisnici, zaposleni, isporučioci, distributeri)

- lanca aktivnosti podrške (banke, advokatske

računovodstvene kancelarije, zakonodavstvo i vladine agencije).

\subsection{Menadžment e-poslovanjem}

Menadžment e-poslovanja integriše: strategiju i operacionalizaciju e-poslovanja.

Strategija e-poslovanja definiše sve poslovne aktivnosti čiji je krajnji cilj profit kompanije i zadovoljstvo korisnika, a zasniva se na sintagmi globalizacije.

Operacionalizacija e-poslovanja su sve aktivnosti kojima se strategija e-poslovanja transformiše u konkretne zadatke koji imaju jasne odrednice aktivnosti, nosioca, roka i budžeta realizacije.

Operativno e-poslovanje obuhvata sledeće elemente:

- e-proizvodnja i e-proizvodi

- e-tehnologija

- distributivni lanci

- elektronska zaštita i pravo.

E-proizvodnja i e-proizvodi podrazumevaju distribuirano okruženje koje obezbeđuje rad na daljinu: "telework", rad kod kuće, virtuelni timovi, procedure na intranetu i $\mathrm{dr}$.

E-tehnologija podrazumeva tehnologije koje omogućavaju obavljanje poslovnih procesa onlajn, veb softverske tehnologije (ASP, PHP, SQL, Java...), dizajn (web design) i njihove upotrebljivosti na nivou potreba korisnika ("usability"), od kojih su najznačajnije aktivnosti razmene između zainteresovanih strana u poslovnom procesu (B2C, B2B, B2E, B2G, C2G, eBanking ...).

Distributivni lanci predstavljaju prilagođene modele lanaca distribucije fizičkih i nematerijalnih dobara i usluga, kako bi se uspešno završio proces razmene dobara između zainteresovanih strana $u$ procesu onlajn poslovanja.

Elektronska zaštita $i$ pravo predstavlja pravni okvir koji osigurava bezbedno poslovanje sa maksimalno smanjenim rizicima da bi kompletan proces onlajn poslovanja bio uređen i u skladu sa potrebama zainteresovanih strana [2].

\subsection{Razvoj e-poslovanja}

Razvoj e-poslovanja prema [4], može se podeliti na sledeće faze:

- veb prezentacija,

- e-kupovina i prodaja,

- e- deljenje informacija,

- inteligentno e-poslovanje.

U prvoj fazi kompanija samo postavlja svoju veb prezentaciju na internetu u cilju ostvarenja komunikacije sa sadašnjim i potencijalnim korisnicima.

U drugoj fazi pored veb prezentacije, obavlja se i onlajn kupovina i prodaja.

Treća faza uključuje e-deljenje informacija između stejkholdera, tj. svih zainteresovanih strana za poslovanje jedne kompanije.

U četvrtoj fazi (inteligentno e-poslovanje), dolazi do integracije i obavljanja svih poslovnih procesa elektronskim putem.

Kako razvoj e-poslovanja teče od prve ka četvrtoj fazi, dolazi do povećanja prodaje, povećanja brzine isporuke, kao i kvaliteta proizvoda i usluga (slika 1).

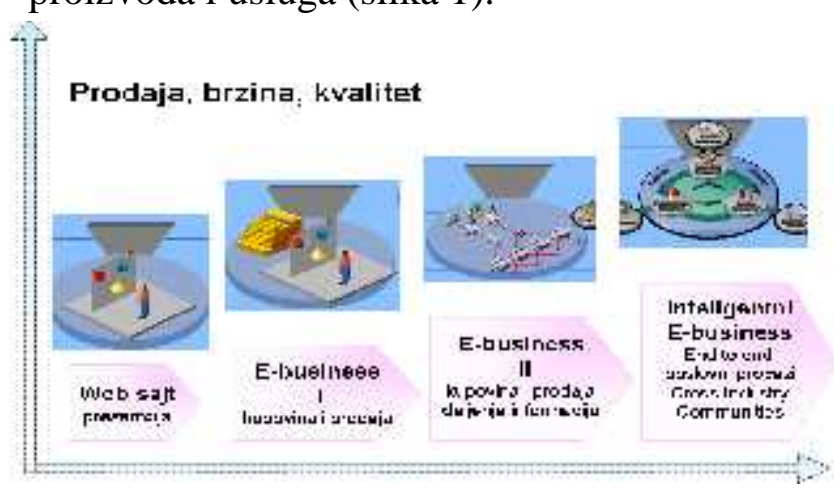

Slika 1. Razvoj e-poslovanja (izvor: [4])

\subsection{Prednosti i nedostaci e-poslovanja}

Osnovne prednosti e-poslovanja su sledeće:

- odsustvo za potrebom skupe nekretnine, aranžiranja izloga;

- minimalni broj angažovanog prodajnog osoblja;

- mogućnost prodaje korisnicima bez obzira na njihovo geografsko područje;

- mogućnost trenutne komunikacije; 
- mogućnost prezentovanja ponude putem interaktivnog multimedijalnog kataloga (čiji obim ionformacija može da se proširuje po želji);

- mogućnost brzog prilagođavanja prodajnih cena aktuelnoj tražnji i nivou zaliha;

- mogućnost prilagođavanja zahtevima korisnika.

Osnovna ograničenja e-poslovanja:

- mnogi potencijalni korisnici još uvek ga ne primenjuju

- nedostatak širokopojasnih veza interneta

- e-kupovina preko Interneta zahteva veće poverenje (sa obe strane)

- opasnost od ugrožavanja privatnosti: lične (proaktivni marketing, cookie i dr.), finansijske (zloupotreba kartica)

- problem stvarnog postojanja prodavca na internetu

- nivo bezbednosti obavljanja transakcije [3]

\subsection{Karakteristike informatičkog društva}

Motor razvoja informatičkog društva čine [5] :

- otvoren, svima dostupan i kvalitetan pristup Internetu

- razvijeno e-poslovanje, uključujući: eupravu, e-trgovinu, e-pravosuđe, ezdravlje i e-obrazovanje.

Prema podacima Republičkog zavoda za statistiku (Tabela 1), evidentno je da, sa stanovišta e-poslovanja, Srbija vidno zaostaje za Evropskom unijom (EU 28). Cilj je da Srbija do 2020. godine po pokazateljima razvijenosti informacionog društva dostigne prosek EU.

Tabela 1. Pokazatelji razvoja informatičkog društva (izvor: [5])

\begin{tabular}{|l|c|c|c|c|}
\hline država & \multicolumn{2}{|c|}{ Srbija } & \multicolumn{2}{c|}{ EU 28 } \\
\hline godina & $\mathbf{2 0 0 9}$ & $\mathbf{2 0 0 8}$ & $\mathbf{2 0 0 9}$ & $\mathbf{2 0 0 8}$ \\
\hline $\begin{array}{l}\text { domaćinstava koja } \\
\text { poseduju Internet } \\
\text { priključak (\%) }\end{array}$ & 36,7 & 33,2 & 65,0 & 60,0 \\
\hline $\begin{array}{l}\text { širokopojasni pristup } \\
\text { Internetu (\%) }\end{array}$ & 22,9 & 15,5 & 56,0 & 49,0 \\
\hline $\begin{array}{l}\text { Stepen } \\
\text { Sofisticiranosti } \\
\text { servisa e-uprave (\%) }\end{array}$ & 46,0 & 38,0 & 83,0 & 76,0 \\
\hline
\end{tabular}

E-poslovanje ima više dodirnih tačaka sa uslužnim delatnostima, budući da se realizuje u njihovom okrilju (na primer primena e-poslovanja u prodaji polovnih automobila, rezervnih delova, i dr.), štaviše, zahvaljujući e-poslovanju nastao je čitav niz novih usluga (na primer e-banking, ebuking, i dr.). Iz tih razloga od interesa je da se razmotri e-poslovanje u uslužnim delatnostima. Stoga se u narednom tekstu detaljnije razmatra uslužna delatnost.

\section{Uslužne delatnosti}

\subsection{Privredni sektor}

Privreda je osnovna društvena delatnost koja u užem smislu obuhvata proizvodnju i raspodelu proizvoda, a u širem smislu obuhvata sve vrste delatnosti i usluga koje omogućavaju ispunjenje svih ljudskih potreba. Može se razlikovati pojam nacionalna privreda, koji se odnosi na delatnosti u okviru jedne države, i svetska privreda, koji se odnosi na delatnost posmatrano na globalnom nivou, u kojoj svaka zemlja daje svoj doprinos.

Uobičajeno je da se privreda deli na sektore, koje sačinjavaju odgovarajuće privredne grane, $\mathrm{i}$ to:

- Primarni sektor: poljoprivreda, lov, ribolov i šumarstvo

- Sekundarni sektor: industrija, rudarstvo, građevinarstvo i proizvodno zanatstvo

- Tercijarni sektor: saobraćaj, trgovina, turizam, ugostiteljstvo, zanatstvo, bankarstvo i komunalna privreda

- Kvartarni sektor: obrazovanje, nauka, kultura, informacije, zdravstvo i socijalna zaštita (odnosi se na vanprivredne delatnosti, a nekada je smatran delom tercijarnog sektora) [6].

\subsection{Uslužni sektor}

Tercijarni sektor privrede je poznat i kao uslužni sektor ili servisna industrija (engl. service industry). Uslužni sektor se sastoji od "mekih" delova privrede, tj, aktivnosti gde ljudi nude svoje znanje i vreme da uvećaju produktivnost, performanse, potencijal i održivost. Osnovna karakteristika ovog sektora je realizacija usluga umesto krajnjih proizvoda. Usluge 
(takođe poznate i kao "neopipljivi proizvodi”) uključuju pažnju, savet, pristup, iskustvo i diskusiju. Produkcija informacija generalno se tiče usluga. Uslužni sektor uključuje korisnost usluga za drugo poslovanje kao i finalnih korisnika. Usluge mogu da uključe transport, distribuciju i prodaju roba od strane proizvođača korisnicima, što može biti slučaj kod veleprodaje ili maloprodaje, ili da uključe korisnost usluga, kao što su suzbijanje štetočina ili zabava. Robe mogu biti transformisane u proces pružanja usluge, što je slučaj kod hotelske industrije. Međutim, fokus je na interakciji između ljudi i pružanju usluge korisniku umesto transformaciji fizičke robe.

Poslednjih 100 godina, postoji bitan pomak od primarnog i sekundarnog sektora ka tercijarnom sektoru, posebno kod industrijalizovanih zemalja. Ovaj pomak je poznat kao tercijarizacija ili postindustrijalizacija (deindustrijalizacija) i manifestuje se $\mathrm{u}$ raspodeli bruto društvenog prihoda BDP po sektorima, slika 2.

Uslužni sektor je danas najveći privredni sektor na zapadu, i takođe je sektor koji ima najbrži rast. U pojašnjenju rasta uslužnog sektora ranih devedestih godina prošlog veka govori činjenica o raspodeli radne snage koja radi u uslužnom sektoru (u SAD $70 \%$, u Japanu $60 \%$, a na Tajvanu 50\%), a njihove zarade su kao i kod proizvodnih radnika, neretko i veće [7].

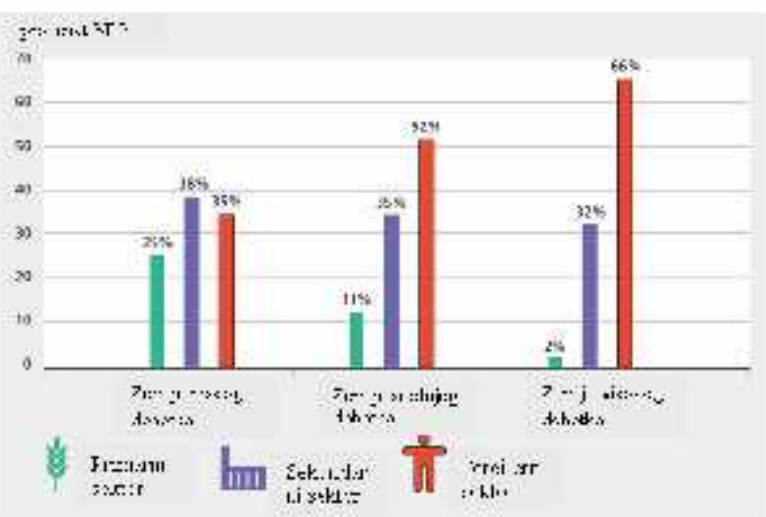

Slika 2. Struktura sektora svetske ekonomije u 1995. godini (izvor: [8 ])

Udeo usluga u svetskoj ekonomiji rastao je je rapidno tokom 20-tog veka. Primera radi, u SAD, samo servisni sektor je ostvarivao više od 1/2 BDP u 1929., 3/4 u 1978., a više od 3/4 u 1993. godini. Globalno posmatrano, na početku 21. veka uslužni sektor beleži više od $3 / 8$ od BDP. Kako se uvećavala automatizacija proizvodnih kapaciteta, manje radne snage je uspevalo da proizvede više roba, tako da su uslužne funkcije distribucija, menadžment, finansije i prodaja postale relativno značajnije [9].

Prema klasifikaciji delatnosti [10], uslužni sektor obuhvata sledeće privredne grane, i to:

- saobraćaj

- trgovina

- turizam

- ugostiteljstvo

- zanatstvo

- bankarstvo

- komunalna delatnost

\subsection{Definicija usluge}

Najjasniju i najpoznatiju definiciju usluga izneo je Adam Smit, kojom je primetio da, za razliku od robe, "kod pruženih usluga njihove performanse uglavnom nestaju istog trenutka, i retko ostavljaju bilo kakav trag iza sebe ili vrednost, ali se istog kvaliteta mogu nabaviti kasnije" [11].

Ova karakteristika čini uslužne delatnosti teško merljivim na način na koji se vrednuje roba poput čelika ili pšenice, posebno pošto usluge imaju tendenciju da se neprimetno stope sa ostalim aktivnostima.

Usluga je nešto što se i proizvodi i troši (ili konzumira) istovremeno [12].

Usluge su rezultat bar jedne aktivnosti koja se obavlja na interfejsu između isporučioca i korisnika, po materijalnosti najčešće su kombinovani proizvodi. Ono što ovu kategoriju proizvoda razlikuje od ostalih je to što on nastaje aktivnostima koje se delimično ili potpuno odvijaju u prisustvu korisnika. Dakle, bitna karakteristika usluge kao proizvoda je činjenica da ona uvek podrazumeva uključivanje korisnika (potrošača) u sam proces nastajanja proizvoda, odnosno postoji direktan kontakt proizvođač - korisnik. 
Može se konstatovati da zapravo usluga i ne postoji, već samo rezultat njene realizacije može biti primećen. Primera radi, kada se obavlja usluga podšišivanja, usluga je potrošena istovremeno dok je proizvedena, ali je efekat usluge očigledan i trajaće neko vreme. U cilju razlikovanja proizvoda kao robe i proizvoda $\mathrm{u}$ obliku usluge u tabeli 2 dat je uporedni prikaz njihovih najznačajnih razlika.

Tabela 2. Razlika između proizvoda $i$ usluge (Izvor: [12])

\begin{tabular}{|c|c|}
\hline \multicolumn{2}{|c|}{ Proizvod } \\
\hline u obliku robe & u obliku usluge \\
\hline Proizvod je opipljiv & Usluga je neopipljiva \\
\hline $\begin{array}{l}\text { Vlasinštvo se prenosi } \\
\text { u trenutku kupovine }\end{array}$ & $\begin{array}{l}\text { Vlasništvo se uopšte ne } \\
\text { prenosi }\end{array}$ \\
\hline $\begin{array}{l}\text { Proizvod se može } \\
\text { preprodati }\end{array}$ & $\begin{array}{l}\text { Naknadna prodaja nije } \\
\text { moguća }\end{array}$ \\
\hline $\begin{array}{l}\text { Proizvod se može } \\
\text { pokazati pre } \\
\text { kupovine }\end{array}$ & $\begin{array}{l}\text { Uslužni proizvod ne } \\
\text { postoji pre kupovine }\end{array}$ \\
\hline $\begin{array}{l}\text { Proizvod se može } \\
\text { uskladištiti }\end{array}$ & $\begin{array}{l}\text { Uslužni proizvod se ne } \\
\text { može uskladištiti }\end{array}$ \\
\hline $\begin{array}{l}\text { Proizvodnja prethodi } \\
\text { potrošnji }\end{array}$ & $\begin{array}{l}\text { Proizvodnja i potrošnja } \\
\text { se događaju istovremeno }\end{array}$ \\
\hline $\begin{array}{l}\text { Proizvodnja i } \\
\text { potrošnja mogu biti } \\
\text { prostorno odvojene }\end{array}$ & $\begin{array}{l}\text { Proizvodnja i potrošnja } \\
\text { se moraju događati na } \\
\text { istoj lokaciji }\end{array}$ \\
\hline $\begin{array}{l}\text { Proizvod se može } \\
\text { transportovati }\end{array}$ & $\begin{array}{l}\text { Uslužni proizvod se ne } \\
\text { može transportovati }\end{array}$ \\
\hline $\begin{array}{l}\text { Proizvođač prodaje } \\
\text { proizvod }\end{array}$ & $\begin{array}{l}\text { Korisnik učestvuje } \\
\text { direktno u proizvodnom } \\
\text { procesu i može čak } \\
\text { izvesti deo proizvodnje }\end{array}$ \\
\hline $\begin{array}{l}\text { Funkcije proizvodnje } \\
\text { i prodaje su odvojene }\end{array}$ & $\begin{array}{l}\text { Prodaja i proizvodnja se } \\
\text { ne mogu funkcionalno } \\
\text { razdvojiti }\end{array}$ \\
\hline
\end{tabular}

Budući da svaku robu bar delimično prati usluga, i obrnuto, svaka usluga je delimično praćena robom (slika 3), može se zaključiti da je između proizvoda $u$ obliku robe i proizvoda u obliku usluge teško povući oštru granicu. Stoga kada se govori o proizvodu čini se da je ispravnije govoriti o uslužnom proizvodu.

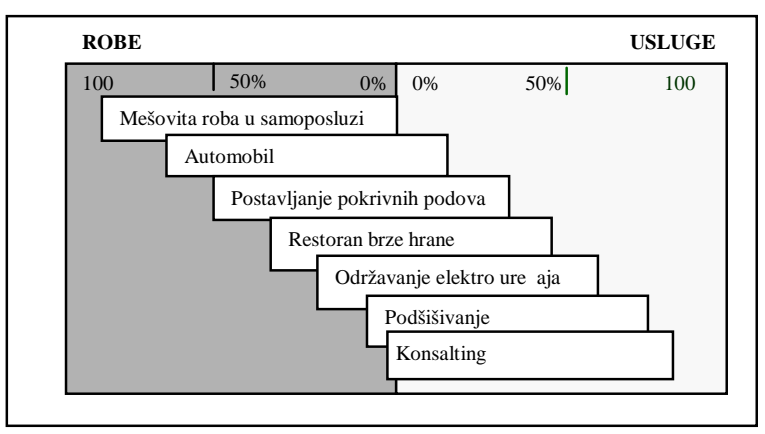

Slika 3. Odnos učešća proizvoda i usluge (izvor: [12])

\subsection{Uslužni proizvod}

Uslužni proizvod se može definisati kao proizvod koji se sastoji od roba i usluga $u$ paketu, odnosno fizičkih predmeta i robe koje olakšavaju posao, koristi koje se osećaju ili eksplicitne usluge, kao i psihološke koristi ili implicitne usluge.

Primera radi, kod jednog restorana struktura uslužnog proizvoda se može opisati na sledeći način. Fizičke predmete čini oprema datog restorana, hrana, picee, salvete itd.. Koristi koje se osećaju predstavljaju ukus i miris hrane, usluga konobara, govor i izgled ljudi. Psihološke koristi uključuju komfor ambijenta, ugled i osećaj zadovoljstva.

Uslužni proizvod podrazumeva kompletnu uslugu, u najširem smislu, skup materijalnog i nematerijalnog u jednom, povezivanje brojnih aktivnosti i ljudi radi stvaranja satisfakcije i kompletnog pozitivnog utiska u očima korisnika.

Uslužni proizvod (kao paket) se sastoji iz sledećih komponenata:

- Proizvod

- Usluga

- Uslužni ambijent

- Isporuka usluge

Proizvod je ono što kompanija prenosi korisniku, a što može biti dodirnuto, dakle on je opipljiv i fizički realan. Primer: kod bankarskog poslovanja to može biti kreditna kartica, ili CD koji se koristi za e-banking.

Usluga predstavlja ključnu performansu koja se prodaje korisniku, a čini je uređen sled događaja koji su osmišljeni da se ostvari željeni rezultat i uključuje sve interakcije korisnika sa personalom firme. Primer: kod 
bakarskog poslovanja to može biti procedura podizanja kredita, od podnošenja zahteva, pa do realizacije kredita.

Uslužni ambijent je fizičko okruženje usluge. Primer: kod bankarskog poslovanja to može biti enterijer i eksterijer filijale (koji služi za neverbalnu - proksemičnu komunikaciju), dostupnost bankomata.

Isporuka usluge se odnosi na ono što se zaista događa kada korisnici kupuju uslugu. Primer: kod bankarskog poslovanja to su glavne odrednice kvaliteta, kao što su tačnost, stručnost i ljubaznost osoblja u traženju podataka, davanju informacija i realizaciji konkretnog bankarskog posla.

Usluge se mogu klasifikovati po osnovu:

- Tržišta (organizacioni korisnici usluga, finalni korisnici usluga)

- Opipljivosti (iznajmljivanje sredstava usluga, vlasništvo proizvoda usluga, nerobni proizvodi usluga)

- Stručnosti (profesinalne i neprofesionalne usluge)

- Ciljeva pružanja usluga (profitne i nepro-fitne usluge)

- Stepena regulacije (regulisane i neregu-lisane usluge)

- Stepena radne intenzivnosti (tehnički za-snovane usluge, radno zasnovane usluge)

- Stepena korisničkog kontakta (visok i nizak korisnički kontakt usluga).

Faktori koji utiču na razvoj usluga su:

- Vremenski zahtevi. Primer: intenzivni način života smanjuje slobodno vreme ljudima, stoga oni sve više koriste usluge restorana umesto da samostalno pripremaju hranu.

- Tehnologija samousluživanja. Primer: razvoj IKT omogućio je plaćanje računa putem interneta, kupovinom od kuće.

- Outsourcing. Primer: kompanije realizuju glavne aktivnosti, a ostale usluge pribavljaju od drugih, za to specijalizovanih kompanija.

- Konkurencija. Primer: konkurencija primorava kompaniju da svoju ponudu obogaćuje uključenjem usluge kao nezaobilaznog faktora ostvarivanja konkurentnosti.

\subsection{Usluge i nove tehnologije}

Elektronsko poslovanje je primenjivo u svim poslovnim delatnostima, u manjem ili većem stepenu, u zavisnosti od karaktera poslovanja. U nekim delatnostima nije moguće sve poslovne aktivnosti pokriti onlajn transakcijama. U slučaju prodaje materijalnih dobara, informacije o predmetu, uslovima prodaje i kupoprodajne transakcije se obavljaju elektronski, dok se distribucija robe obavlja na tradicionalni, fizički način. Sa druge strane, u nekim delatnostima moguće je organizovati potpuno onlajn poslovanje, kao što je, na primer, područje usluga.

U nastavku će detaljnije biti opisano elektronsko poslovanje u trgovini, bankarstvu i turizmu - granama uslužne delatnosti na koje je primena IKT i interneta imala poseban uticaj. Otuda česta primena prefiksa »elektronski « u nazivima ovih grana delatnosti - elektronska trgovina, elektronsko bankarstvo i elektronski turizam.

\section{Elektronska trgovina}

Elektronska trgovina ili e-trgovina (eng. ecommerce) - predstavlja komponentu elektronskog poslovanja, koja opisuje procese kupovine, prodaje i razmene dobara, usluga i informacija, putem računarskih mreža koje uključuju i internet. Podrazumeva kompletan prodajni proces koji obuhvata marketing, prodaju i posleprodajne aktivnosti. Termin elektronska trgovina može se definisati i kao proces upravljanja online finansijskim transakcijama od strane pojedinaca ili kompanija. Ovaj proces uključuje kako maloprodajne, tako i veleprodajne transakcije. Finansijske transakcije se obavljaju posredstvom informacionokomunikacione i mobilne tehnologije. Fokus elektronske trgovine je u sistemima i procedurama pomoću kojih dolazi do razmene različitih finansijskih dokumenata i informacija [2].

Prednosti elektronske trgovine su:

- brz pristup informacijama, a time $\mathrm{i}$ bolja dostupnost proizvoda i usluga na tržištu 
- brz i jednostavan transfer prateće dokumentacije između zainteresovanih strana

- otvorenost tržišnog prostora zahvaljujući informacijama

- veća mogućnost analize proizvoda i usluga i razmene iskustava

- mogućnost istraživanja tržišta i plasmana proizvoda u skladu sa zahtevima tržišta

Najveći rizici elektronskog trgovanja proizilaze iz:

- zloupotrebe i uništenja podataka

- narušavanja privatnosti klijenata

Poslovne aktivnosti prodavca u uslovima elektronske trgovine znatno se menjaju u odnosu na njihovu ulogu u klasičnoj trgovini. Javljaju se neki novi, a nestaju neki stari zadaci prodavca. Nov način trgovanja zahteva neka nova znanja i prilagođavanje izmenjenim uslovima, pre svega novim, virtuelnim poslovnim prostorima u kojima se odvija trgovina. Aktivnosti prodavca u elektronskoj trgovini su:

- izbor modela elektronskog prodajnog mesta

- uspostavljanje elektronskog prodajnog mesta

- razvoj elektronskog marketinga

- kreiranje elektronske poslovne dokumentacije

- izbor i obuka prodajnog osoblja

- elektronska prodajna operativa u mrežnom okruženju

\section{Elektronsko bankarstvo}

U uslovima vrlo jake konkurencije, gde postepeno nestaju razlike između banaka, investicionih banaka, brokerskih firmi i osiguravajućih kompanija, finansijske organizacije su pod stalnim pritiskom da zadrže korisnike svojih usluga, smanje troškove, upravljaju rizikom i koriste tehnologiju kao izvor konkurentske prednosti. Model globalne organizacije i jake konkurencije zahteva novu koncepciju pristupa banaka u njihovom poslovanju, o čemu svedoče sve veća ulaganja u specijalizovanu i prema klijentu orijentisanu tehnologiju. Internet je jedna od tih tehnologija [2].
Elektronsko bankarstvo (eng. e-banking), odnosno - internet bankarstvo, predstavlja obavljanje bankarskih transakcija posredstvom interneta. Karakteristike obavljanja bankarskih transakcija u internet bankarstvu su:

- nije potreban specijalan softver i ne postoje podaci uskladišteni na klijentovom hard disku, pa je veća sigurnost pri obavljanju transakcija

- pristup banci i računu je moguć sa bilo kog mesta na svetu, pod uslovom da na tom mestu postoji računar priključen na internet

- banka brine o održavanju sopstvenog hardverskog i softverskog sistema zaštite

- moguće je i obavljanje onlajn transakcija

Neke od mogućnosti e-banking sistema (za poslovnu i personalnu upotrebu) su:

- pregled stanja na računu $\mathrm{i}$ istorije plaćanja, u bilo koje vreme

- stanje računa, trajni nalozi, stanje kartica, i sl.

- transfer novca i plaćanje računa (trgovina, plaćanja u inostranstvu, trgovinski onlajn nalozi),

- štednja, krediti i ostale bankarske usluge

- dostupnost 24 sata na dan.

Internet bankarstvo ima niz prednosti u odnosu na takozvano tradicionalno poslovanje banaka. Prednosti se uglavnom ogledaju u:

- vremenskoj neograničenosti,

- prostornoj neograničenosti

- brzini obavljanja transakcija

- niskoj ceni

- širokom asortimanu bankarskih proizvoda i usluga

Glavni ograničavajući faktori, koji uslovljavaju pristanak potrošača na ovu vrstu bankarstva su: sigurnost i privatnost.

Nedostaci internet bankarstva najviše su izraženi u:

- odsustvu potpune sigurnosti pri obavljanju poslovanja

- nepostojanju kompletne zakonske regulative

- nedostatku privatnosti 
- otuđenosti i odbojnosti prema inovacijama

- opasnosti od zloupotrebe internet bankar-stva u kriminalne svrhe

\section{Elektronski turizam}

Razvojem elektronskog poslovanja, stvaraju se $\mathrm{i}$ novi tipovi proizvoda i usluga $u$ turističkoj industriji. U proteklih 30 godina, zabeležena su tri glavna talasa inovacija IKT u turističkom sektoru.

Prvi veliki uticaj IKT-a na turistički sektor bilo je predstavljanje i uvođenje kompjuterskog rezervacionog sistema (Computer Reservation System - CRS) sedamdesetih godina 20. veka. Ovaj sistem je uglavnom bio razvijen za potrebe avio kompanija, tur-operatora i internacionalnih hotelskih lanaca. CRS je kompjuterizovani sistem koji omogućava direktan pristup putem terminala za proveru raspoloživosti kapaciteta, rezervacija i štampanje karata.

U osamdesetim godinama 20. veka, nastao je globalni distributivni sistem (Global Distribution System - GDS) baziran na kompjuterskom rezervacionom sistemu, koji je objedinjavao širok asortiman usluga i prozvoda i omogućavao globalnu distribuciju informacija.

Globalnim širenjem interneta devedesetih godina 20. veka, CRS i GDS su postali manje značajni, ali oni su pružili turističkim kompanijama tržišnu prednost za dugi niz godina, $\mathrm{u}$ transferu informacija $\mathrm{u}$ okviru turističke industrije. Danas, internet predstavlja svakako najznačajni talas uticaja IKT-a na turistički sektor.

U turističkoj industriji, sve više usluga koje se pružaju turistima zasniva se na upotrebi interneta kao glavnog komunikacionog kanala, koji omogućava istovremeno smanjivanje troškova poslovanja i povećanje broja klijenata. U praksi to znači da turisti imaju mogućnost direktne komunikacije sa pružaocima turističkih usluga i u mogućnosti su da identifikuju, zadovolje pa čak i promene zahteve za turističkim proizvodima, a sa druge strane - pružaoci usluga mogu efikasnije da udovolje sve kompleksnijim zahtevima svojih korisnika.
Veb sajt je postao aktivan marketinški alat koji omogućava korisnicima traženje informacija, planiranje i ugovaranje odmora, i sve to od kuće - 24 sata na dan. Široka lepeza turističkih proizvoda može biti ponuđena, visoka transparentnost i mogućnost da se proizvod ili usluga pogleda pre konačne kupovine, čine internet najatraktivnijim kanalom distribucije proizvoda.

Internet distribucija turističkih proizvoda može da generiše značajno smanjenje troškova i prednost za pružaoce usluga, tako što omogućava uspešno i efikasno dolaženje do novih klijenata. Do 2003. godine turizam je već bio vodeći sektor po obimu onlajn prodaje, u odnosu na sve druge sektore unutar Evropske unije.

Upravljanje odnosima sa kupcima (Customer Relationship Management) je koncept koji u elektronskom poslovanju u turizmu doživljava rast. Ovde su lični odnos prema klijentu i odabir ponuda ključni za uspeh $\mathrm{u}$ poslu. Glavni cilj je povećanje profita i optimizacija troškova, kroz poboljšanje zadovoljstva kupaca preko unapređene interakcije u svakoj dodirnoj tački sa klijentom. Ovo se može postići boljim razumevanjem klijenata, ponudom odgovarajućih usluga - proizvoda u pravo vreme, zasnovano na analizi kupovnih navika klijenta.

\section{Trend razvoja e-poslovanja u budućnosti}

Što se tiče daljeg trenda razvoja elektronskog poslovanja u budućnosti, istraživanja ukazuju da će on ići u pravcu razvoja uslužnih inovacija.

Istraživanje uslužnih inovacija obuhvata različite pristupe i perspektive [13]. Analiza karakterističnih osobina inovacije usluga otkriva tri različite dimenzije, kao što je ilustrovano na slici 4. Prvo, sektorska dimenzija se odnosi na inovacije primenjene na industrije unutar sektor usluga. Drugo, aktivnost ili poslovna dimenzija podrazumeva aktivnosti vezane za inovacije usluga, bez obzira na vrstu sektora u kojima se nalaze. Treće, agent dimenzija podra- 
zumeva da je inovacija usluge rezultat neke koprodukcije između različitih agenata.

Sektorska dimenzija se odnosi na inovacije u sektoru usluga, javnom ili privatnom sektoru. Takve inovacije obuhvataju makro i mezo ekonomski nivo, pri čemu sektor usluga angažuje oko 70 odsto od ukupnog broja zaposlenih (broj preduzeća) u Evropskoj uniji (EU), SAD i drugim razvijenim regionima. Najnaprednije ekonomije su uslužno sektorski orijentisane i inovacije $u$ ovom makro i mezosektorskom nivou mogu značajno uticati na veći deo društva.

Aktivnost dimenzija, na ovom nivou, kao što je prikazano na slici 4, razlike između uslužne inovacije i inovacije robe se zamagljuju i mogu postati irelevantne, jer usluga prevazilazi granice uslužnog sektora na mikro nivou. Pošto se sektorske granice uklanjaju, proizvođači sve više nude miks usluga $i$ roba, a usluge su relevantne dimenzije ekonomske aktivnosti $u$ sektorima, kao što su poljoprivreda i proizvodnja. Pošto uslužno-orjentisane inovacije mogu biti proizvedene u bilo kojoj vrsti poslovanja ili sektora, u suprotnosti sa sektorskom dimenzijom, granice između industrija ovde više nemaju značaja.

Agent dimenzija je značajna budući da inovacije usluga takođe uključuju različite agente, a ne samo izolovane firme ili državne organe. U ovoj dimenziji, kao što je prikazano na slici 1 , inovacija usluga može biti ishod inovacionih mreža u kojima različiti agenti sarađuju na koprodukciji usluge zasnovane na rezultatu inovacija. Razna razmatranja mrežnih inovacija usluga oslanjaju se na primenu multi - agent okvira. Ova teorija zaslužuje da bude proširena i testirana iz evolucione perspektive jačanja znanja inovacija usluga.

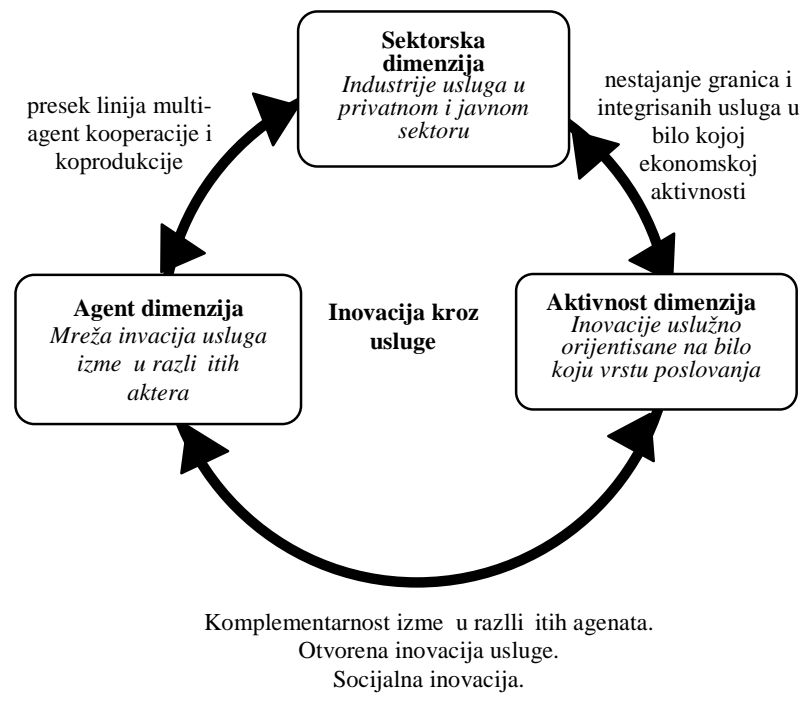

Slika 4. Višedimenzioni okvir inovacija usluga, (izvor [13])

Trendovi ukazuju na sve veću upotrebu IKT koje se pojavljuju u skladu sa značajem organizacione inovacije, koja je usko vezana za inovacije usluga, iako varira u zavisnosti od veličine firme.

Uprkos rastućim interakcijama sa novim tehnologijama, naročito IKT, većina inovacija usluga i dalje ostaje ne-tehnička.

Polje inovacija usluga je bogato i raznovrsno, i ima izrazitu složenost i višestranu prirodu.

\section{Zaključak}

$\mathrm{U}$ ovom radu razmotren je aktuelni trend poslovanja, izražen kroz glavne karakteristike na globalnom planu, sa fokusom na elektronsko poslovanje u uslužnom sektoru. Jedna od važnih karakteristika trenda je da ovakvo poslovanje doprinosi tome da poslovanje bude efektivan i efikasan način organizacije poslovanja u mrežnom okruženju, zasnovanom na primeni IKT, a posebno interneta. Sa operativnog stanovišta posmatrano, e-poslovanje privrednih subjekata danas pokriva: e-proizvodnju, e- proizvode, etehnologiju, distributivne lance, elektronsku zaštitu i pravo. U širem kontekstu posmatrano, e-poslovanje uključuje i ostale sfere društvenog života: e-upravu, e-trgovinu, epravosuđe, e-zdravlje i e-obrazovanje.

Privreda, kao osnovna društvena delatnost deli se na primarni, sekundarni, tercijarni i 
kvartarni sektor, od čega poseban značaj ima tercijarni, odnosno uslužni sektor, koji je danas dominantan privredni sektor, budući da ima najbrži rast.

U osnovi uslužnog sektora je uslužni proizvod koji podrazumeva skup materijalnog $\mathrm{i}$ nematerijalnog $\mathrm{u}$ jednom, povezivanje brojnih aktivnosti i ljudi radi ostvarenja pozitivnog utiska i korisnika, kome poseban doprinos daje e-poslovanje.

Trend razvoja e-poslovanja u budućnosti može se predvideti na osnovu razvoja inovacija usluga koji ukazuje da se sektorske granice sve više uklanjaju, proizvođači sve više nude miks usluga i roba, tako da usluge, posebno u e-okruženju postaju relevantne dimenzije ekonomske aktivnosti, ne samo u tercijarnom sektoru, već i ostalim sektorima.

\section{Bibliografija}

1. Milošević D, Strategija rasta i razvoja preduzeća, Visoka škola za poslovnu ekonomiju i preduzetništvo Beograd, 2012.

2. Ranđić, S, Skorup, A. Poslovanje preko Interneta, ICIM Plus, Kruševac, 2008.

3. http://sr.wikipedia.org/sr/ лектронско послов ње, wikipedia, ЕР 2013., preuzeto 05.04.2013.

4. Živadinović J., Radovanović S, Elektronsko poslovanje, Visoka škola za poslovnu ekonomiju i preduzetništvo Beograd, 2010.

5. Strategija razvoja ID 2012, Strategiju razvoja informacionog društva $u$ Republici Srbiji do 2020. godine, „Službeni glasnik RS” br. 65/08, 2012.

6. http://sr.wikipedia.org/sr/ ривред , wikipedia PR, 2013, preuzeto 08.04.2013.

7. http://en.wikipedia.org/wiki/Tertiary_sect or_of_the_economy, wikipedia TS, 2013, preuzeto 08.04.2013.

8. www.worldbank.org/depweb/.../beg_09.p df Growth of the Service Sector, 2009.

9. http://encyclopedia2.thefreedictionary.co $\mathrm{m} /$ Service+Industry, Service industry, 2013., preuzeto 09.04.2013.

10.http://webrzs.stat.gov.rs/WebSite/userFile s/file/Klasifikacija\%20delatnosti/Klasifik acija.pdf RZS 2013., Klasifikacija delatnosti.

11. Clive H. L., The Service Sector and economic growth, Refresh 22, Spring 1996.

12. Schroeder G. R, Upravljanje proizvodnjom, IV izdanje, MATE doo, Zagreb, 1999.

13. Rubalcaba L., Michel S, Sundbo J, Brown S. W, Reynoso J., Shaping, organizing, and rethinking service innovation: a multidimensional framework, Journal of Service Management, 2012., Vol. 23 No. 5, 2012, pp. 696-715

\section{Istorija rada:}

Rad primljen: 22.05.2013.

Prva revizija: 22.05.2013.

Prihvaćen: 26.05.2013. 